\title{
Photosensitized Water Oxidation Using a Bio-Inspired Manganese Catalyst
}

Erik A. Karlsson, ${ }^{1}$ Bao-Lin Lee, ${ }^{1}$ Torbjörn Åkermark, ${ }^{2}$ Eric V. Johnston, ${ }^{1}$ Markus D. Kärkäs, ${ }^{1}$ Junliang Sun, ${ }^{2}$ Örjan Hansson, ${ }^{3}$ Jan-E. Bäckvall, ${ }^{1}$ Björn Åkermark ${ }^{* 1}$

${ }^{1}$ Dept. of Organic Chemistry, Stockholm University, SE-106 91 Stockholm, Sweden

${ }^{2}$ Dept. of Materials and Environmental Chemistry, Stockholm University, SE-106 91 Stockholm, Sweden

${ }^{3}$ Dept. of Chemistry, University of Gothenburg, P.O Box 462, SE-405 30 Gothenburg, Sweden

*bjorn.akermark@organ.su.se

Keywords: water oxidation, manganese catalysis, artificial photosynthesis

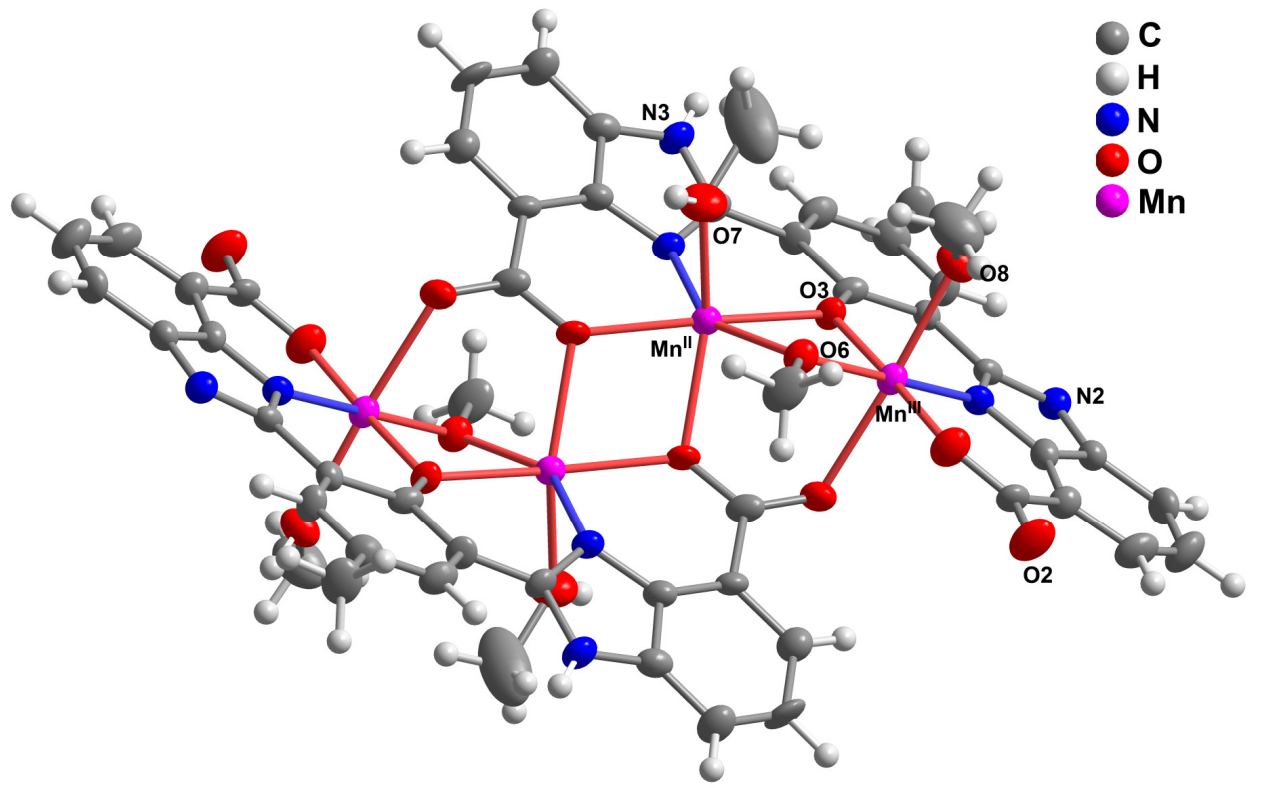

Figure 1. X-ray crystal structure of complex 4 at $50 \%$ probability level.

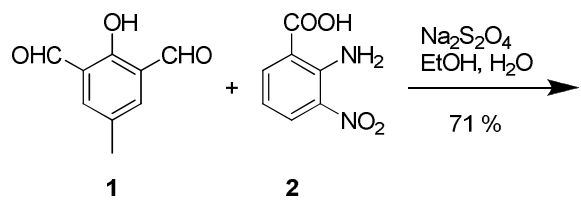

\section{INTRODUCTION}

Water oxidation catalysts are essential in bioinspired systems for solar-driven water splitting. ${ }^{1}$ Several ruthenium catalysts are known, ${ }^{2}$ but so far no manganese-based catalysts have been reported.

\section{RESULTS AND DISCUSSION}

Complex 4, prepared in a simple two-step sequence, has a tetranuclear structure, resembling the OEC in photosystem II. Treatment of 4 with $\mathrm{Ru}(\mathrm{bpy})_{3}{ }^{3+}$ as oxidant led to evolution of oxygen with a TON of 25 . Furthermore, employing visible light together with $\mathrm{Ru}(\mathrm{bpy})_{2}(\text { deeb })^{2+}$ as photosensitizer and $\mathrm{S}_{2} \mathrm{O}_{8}{ }^{2-}$ as electron acceptor, a TON of 4 was achieved.

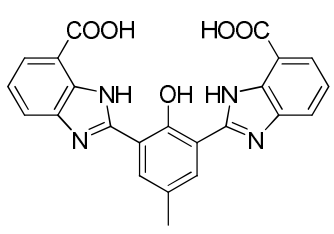

3
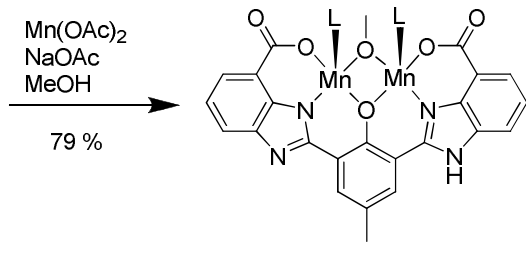

$\mathrm{L}=\mathrm{MeOH} \quad 4$

CONCLUSION

This is, to the best of our knowledge, the first homogeneous manganese complex to catalyze water oxidation using a one-electron oxidant, and also using visible light and a photosensitizer.

\section{ACKNOWLEDGEMENTS}

We thank the K\&A Wallenberg Foundation and the Swedish Energy Authority for financial support.

\section{REFERENCES}

${ }^{1}$ Lewis, N. S.; Nocera, D. G. Proc. Natl. Acad. Sci. U. S. A. 2006, 103, $15729-15735$.

${ }^{2}$ Sala, X.; Romero, I.; Rodríguez, M.; Escriche, L.; Llobet, A. Angew. Chem., Int. Ed. 2009, 48, 2842-2852. 